\title{
Designing an Electronic Shared Care Plan to Enable Person-Centred, Team-Based Home Care
}

\author{
Susi WILKINSON ${ }^{\mathrm{a}, \mathrm{c} 1}$ and Elizabeth M. BORYCKI ${ }^{\mathrm{b}, \mathrm{c}}$ \\ ${ }^{a}$ Interior Health Authority, Kelowna, British Columbia, Canada \\ ${ }^{\mathrm{b}}$ School of Health Information Science, University of Victoria, Canada \\ ${ }^{c}$ Michael Smith Foundation for Health Research, Canada
}

\begin{abstract}
Optimization of interdisciplinary team-based care is an important strategy to improve home health care for older adults. An electronic, shared care plan was designed with aim to support shifts toward greater client and family involvement and interdisciplinary team functioning. Content for the home health collaborative care plan (HHCCP) was determined through a review of existing care plans, engagement with client and family partners, and usability testing by home health clinicians using a paper prototype. Client and family consultation and usability testing led to the identification of new and unique requirements for the HHCCP. We provide an example of how a paper prototype was used to validate and determine additional requirements for electronic clinical documentation and conclude that end users should be involved in the design of electronic clinical documentation as early as possible.
\end{abstract}

Keywords. Electronic shared care plan, patient centred care, home care

\section{Introduction}

British Columbia's health system is progressing through a system-wide redesign to become more person-focused, accessible, sustainable, and achieve better population health outcomes. Important strategies for seniors care are to optimize functioning of home health interdisciplinary teams and linkages with clients' primary care providers and teams. Within Interior Health Authority (IHA), home health interdisciplinary teams currently complete electronic clinical documentation in discipline-specific electronic documents. IHA leaders determined the need to develop an electronic collaborative care plan (HHCCP) in order to enable a person-centred, interdisciplinary team-based approach to delivery of home health services.

A collaborative or shared care plan is both a patient-centred health record that supports communication amongst the health team and a tool for clients to become as involved in their health care as they wish to be [1]. A recent literature review of health care transformations and care plans for frail, multimorbid elderly populations found the care plans did not capture client-reported outcomes nor the monitoring of care interventions [2]. The majority of care plans did not capture client perspectives about

${ }^{1}$ Corresponding Author, Susi Wilkinson, Interior Health Authority, Penticton Health Centre, 740 Carmi Ave, Penticton, BC, Canada, V2A8P9; E-mail: susi.wilkinson@interiorhealth.ca. 
their health needs or what mattered to them in their health care. This paper describes the methodology used to determine the content and other design requirements for the HHCCP. The methodology is novel as it engages client (i.e. patients) and captures information about patient perspectives and outcomes.

\section{Methods}

The initial requirements for HHCCP were to enable all involved home health clinicians to document their discipline-specific goals and interventions of care into a single care plan. The methodology consisted of three steps that were used to identify detailed requirements for the HHCCP: (1) a review of internal and external care plan documents; (2) a consultation with client and family partners; and (3) usability testing using a paperbased prototype.

\subsection{Step 1: Review of Care Plans}

The design team conducted a review of paper and electronic care plan documents used in IHA. Shared care plans provided by the Institute for Healthcare Improvement [3] and the Agency for Healthcare Research and Quality [1] websites were also examined to identify additional information that would be valuable to include in the HHCCP.

\subsection{Step 2: Client and Family Consultation}

The British Columbia Patient Voices Network assisted with identifying adults over the age of 65 years to participate in a virtual focus group that occurred via teleconference and optional videoconference. Focus group participants received a brief description of the project and a sample shared care plan prior to the focus group meeting. The focus group posed two questions:

- How might a shared care plan be helpful or useful to clients and/or families

- What information should be included in the shared care plan.

The focus group teleconference was recorded to allow for review and analysis.

\subsection{Step 3: Paper Prototype Testing}

Content identified in the review of care plans and input from the client/family focus group was used to create the paper prototype. The design team met with representative home health clinicians (test clinicians) from across the IHA region to test the paper prototype according to the following procedure:

- The design team first created two client scenarios to enable a simulation for future use of the electronic HHCCP. The fictional client scenarios described the health and social situation for two imaginary clients previously unknown to home health whose care would involve several different home health disciplines. The scenarios also specified the order of team member involvement, several client goals and related interventions of care.

- The prototype testing sessions were audio-recorded and began with a review of the project, the HHCCP prototype and the test scenario. Each test clinician 
received a paper copy of the HHCCP prototype and a test client scenario to reference during the testing session.

- The first involved clinician described the steps they would take to complete the initial assessment and care planning session with the test client and to complete the HHCCP paper prototype. The design team directed the clinician to think aloud while completing the HHCCP paper prototype.

- The paper HHCCP prototype was then passed to each of the identified additional team members, each of whom were asked to think aloud while documenting their respective additional client goals and care interventions into the HHCCP prototype.

- The design team reviewed the test session audio recordings to document participant questions, areas of confusion and concerns expressed about the HHCCP and incorporated changes into the HHCCP paper prototype.

\section{Results}

All of the methods used to gather HHCCP requirements led to the identification of new and unique requirements for the HHCCP. Content of the HHCCP and the identification source are described in Table 1.

Table 1. Content requirements for the electronic home health collaborative care plan.

\begin{tabular}{|c|c|c|}
\hline Requirement & Description & Source \\
\hline $\begin{array}{l}\text { Client identifying } \\
\text { information }\end{array}$ & $\begin{array}{l}\text { Such as name, address, phone, health number, account } \\
\text { number, primary care provider or most responsible provider. }\end{array}$ & Care plan review \\
\hline $\begin{array}{l}\text { What Matters to } \\
\text { the Client }\end{array}$ & $\begin{array}{l}\text { Free text capturing client's expressions of what matters to } \\
\text { them }\end{array}$ & Care plan review \\
\hline $\begin{array}{l}\text { Health Care } \\
\text { Needs }\end{array}$ & $\begin{array}{l}\text { Free text capturing client's response when clinician asks } \\
\text { "How can I help?" }\end{array}$ & Care plan review \\
\hline $\begin{array}{l}\text { Client } \\
\text { Background }\end{array}$ & $\begin{array}{l}\text { Free text field capturing client's response to inquiry re: } \\
\text { ethnic background, personal identify, or language }\end{array}$ & Care plan review \\
\hline $\begin{array}{l}\text { Culture and } \\
\text { Spiritual Practice }\end{array}$ & $\begin{array}{l}\text { Free text capturing client's response to inquiry re: cultural } \\
\text { or spiritual practices or belief system }\end{array}$ & Prototype testing \\
\hline $\begin{array}{l}\text { Additional } \\
\text { Information }\end{array}$ & $\begin{array}{l}\text { Free text capturing client's response to "What else is } \\
\text { important for your care team to know about you?" }\end{array}$ & $\begin{array}{l}\text { Client \& Family } \\
\text { engagement }\end{array}$ \\
\hline $\begin{array}{l}\text { Formal/Informal } \\
\text { Supports }\end{array}$ & $\begin{array}{l}\text { Free text capturing client's response to inquiry regarding } \\
\text { others who help them with their health. }\end{array}$ & Care plan review \\
\hline Team Members & $\begin{array}{l}\text { Name, discipline, phone number and service end date for } \\
\text { each involved home health team member }\end{array}$ & $\begin{array}{l}\text { Care plan review, } \\
\text { Prototype testing }\end{array}$ \\
\hline Health Conditions & List of active health conditions & Care plan review \\
\hline $\begin{array}{l}\text { Advance Care } \\
\text { Plan }\end{array}$ & $\begin{array}{l}\text { Yes/No/In Progress response and mandatory free text } \\
\text { description if Yes or In Progress is selected }\end{array}$ & Prototype testing \\
\hline $\begin{array}{l}\text { InterRAI Clinical } \\
\text { Assessment } \\
\text { Protocols }\end{array}$ & $\begin{array}{l}\text { For clients assessed using the InterRAI-HC assessment, } \\
\text { there is requirement to align care planning with any } \\
\text { identified clinical assessment protocols }\end{array}$ & Care plan review \\
\hline
\end{tabular}




\begin{tabular}{lll}
$\begin{array}{l}\text { Care Goals and } \\
\text { Next Steps }\end{array}$ & $\begin{array}{l}\text { Client goals and related interventions are documented in the } \\
\text { appropriate category: Functional Mobility; Pain } \\
\text { Management; Medication Management; Bowel/Bladder } \\
\text { Management; Nutrition/Hydration/Swallowing; Cognitive } \\
\text { Functioning; Mental Health and Substance Use; Social } \\
\text { Determinants of Health; Other Health Challenges }\end{array}$ & $\begin{array}{l}\text { Care plan review } \\
\text { Prototype testing }\end{array}$ \\
Team Notes & $\begin{array}{l}\text { Free text used for client-sensitive planning information } \\
\text { which does not appear on client copy of the HHCCP }\end{array}$ & Paper prototype testing \\
Print Client Copy & $\begin{array}{l}\text { Yes/No response indicating if client would like a copy of the } \\
\text { HHCCP }\end{array}$ & $\begin{array}{l}\text { Client \& Family } \\
\text { engagement } \\
\text { Name and }\end{array}$ \\
Credentials & & Care plan review \\
\hline
\end{tabular}

\section{Discussion}

While a review of existing care plans identified most of the content for the HHCCP, additional requirements were determined through consultation with end users of the HHCCP; namely client and family partners and clinicians. All of the client and family partners consulted in this project identified benefits of the HHCCP and provided examples of how they would use the HHCCP if/when it was to become available to them. Clients and families identified a new requirement to ask clients if there was anything else they wanted their care team to know about or consider in their health care and confirmed the importance of offering clients a copy of the care plan. During the paper prototype tests, home health clinicians identified requirements to document advance care plan information, create a section for client-sensitive information that would not appear on the client copy, and to separate the client background, identity, culture and spirituality question into two distinct questions. Clinicians also identified the need to include the service end date for each involved team member.

\section{Conclusions}

We conclude that clients and families should be engaged into the design of clinical documentation that is intended to be shared or used by them. We provided an example of how a paper prototype can be used to define and validate requirements for electronic clinical documentation and also recommend that clinician users become involved early in the design of electronic clinical documentation.

\section{References}

[1] Agency for Healthcare Research and Quality. Develop a Shared Care Plan. Available from: https://www.integrationacademy.ahrq.gov/products/playbooks/behavioral-health-and-primarycare/implementing-plan/develop-shared-care-plan [Accessed April 30, 2019].

[2] Berntsen G, Strisland F, Ing D, Malm-Nicolaisen K, Smaradottir B, Fensli R, Rohne M. The Evidence base for an ideal care pathway for frail multimorbid elderly: Combined scoping review and systematic intervention review. JMIR. 2019;21(4):e12517.

[3] Institute for Healthcare Improvement. My Shared Care Plan. Available from: https://www.ihi.org/resources/Pages/Tools/MySharedCarePlan.aspx [Accessed April 30, 2019]. 